\title{
Hubungan Status Gizi, Pengetahuan, dan Suhu Tubuh dengan Asupan Cairan pada Ibu Hamil di Jakarta Barat
}

\author{
Husnul Mar'ah', Dodik Briawan'2, Ikeu Tanziha ${ }^{3}$ \\ 1,2,3 Program Studi Ilmu Gizi, Fakultas Ekologi Manusia, Institut Pertanian Bogor, Indonesia \\ Email: husnul1412@gmail.com
}

\begin{abstract}
This research has the aim to analyze the relationship of nutritional status, knowledge, body temperature with fluid intake in pregnant women in West Jakarta. This study design used a cross sectional approach, with number of subjects 84 pregnant women in West Jakarta. Sampling using a purposive sampling method. The nutritional status of pregnant women was obtained based on the weight record before pregnancy. Subject knowledge and fluid intake were obtained by interview with questionnaire. The subject's body temperature was measured with a digital thermometer. Analysis of the relationship between nutritional status, knowledge, and body temperature with fluid intake using the Spearman test. Based on the test of the relationship of nutritional status with fluid intake, the value of $p=0,002$ was obtained. Analysis of the relationship of knowledge with fluid intake obtained $p=0,022$ and the relationship between body temperature and fluid intake obtained $p=0,089$. The conclusion that can be obtained is that there is a relationship between, nutritional status, knowledge with fluid intake, and body temperature has no relationship with fluid intake.
\end{abstract}

Keyword: Fluid intake, knowledge, nutritional status, pregnant, temperature

\begin{abstract}
Abstrak
Penelitian ini memiliki tujuan untuk menganalisis hubungan status gizi, pengetahuan, suhu tubuh dengan asupan cairan pada ibu hamil di Jakarta Barat. Desain penelitian menggunakan pendekatan cross sectional dengan jumlah subjek 84 wanita hamil di Jakarta Barat. Pengambilan sampel menggunakan metode purposif. Status gizi ibu hamil diperoleh dengan menganalisis catatan berat badan sebelum hamil. Pengetahuan subjek dan asupan cairan diperoleh dengan wawancara dengan alat bantú kuesioner. Suhu tubuh subjek diukur dengan termometer digital. Analisis hubungan antara status gizi, pengetahuan, dan suhu tubuh dengan asupan cairan menggunakan uji spearman. Berdasarkan uji hubungan status gizi dengan asupan cairan diperoleh nilai $\mathrm{p}=0,002$. Analisis hubungan pengetahuan dengan asupan cairan diperoleh nilai $\mathrm{p}=0,022$ dan hubungan antara suhu tubuh dengan asupan cairan diperoleh nilai $\mathrm{p}=0,089$. Kesimpulan yang dapat diperoleh bahwa terdapat hubungan status gizi, pengetahuan dengan asupan cairan dan suhu tubuh tidak memiliki hubungan dengan asupan cairan.
\end{abstract}

Kata Kunci: Asupan cairan, kehamilan, pengetahuan, status gizi, subu 


\section{PENDAHULUAN}

Asupan cairan dalam tubuh merupakan asupan yang berasal dari minuman, makanan dan hasil metabolisme. Asupan cairan dalam tubuh harus seimbang dengan kebutuhan. Asupan cairan yang tinggi akan menyebabkan status hidrasi menjadi baik (Ariantika and Mardiyati, 2017). Asupan cairan yang kurang dalam tubuh atau dehidrasi dapat mengakibatkan gangguan kesehatan khususnya pada ibu hamil seperti oligohidroamnion, infeksi saluran kemih, hipertensi, persalinan lama, dan gangguan pada janin. Perhitungan kebutuhan cairan mempertimbangkan beberapa faktor seperti ukuran tubuh, suhu, aktivitas fisik, serta kondisi fisiologis seperti kehamilan (Santoso et al., 2011).

Salah satu faktor penentu kebutuhan cairan adalah dimensi ukuran tubuh. Ukuran tubuh seseorang digambarkan dengan pendekatan Indeks Massa Tubuh (IMT), merupakan perbandingan berat dan tinggi badan. Nilai IMT ini digunakan untuk menilai status gizi seseorang. Individu dengan IMT yang tinggi mengarah pada kondisi hidrasi yang kurang (Chang et al., 2016). Total cairan dan cairan diluar sel di awal kehamilan memiliki hubungan dengan IMT (Gernand et al., 2012).

Menurut Khomsan et al. (2009) pengetahuan memengaruhi sikap dan perilaku, korelasinya terhadap pola pikir serta pengalaman pada obyek. Beberapa penelitian menunjukkan bahwa tingkat pengetahuan terkait keseimbangan cairan berkontribusi terhadap asupan cairan selama masa kehamilan. Ibu hamil dan menyusui ditanyakan terkait pengetahuan keseimbangan cairan tubuh menunjukkan 41\% mengatakan jumlah asupan cairan yang sebaiknya dikonsumsi masih dibawah dari kebutuhan serta konsumsi air mereka $<2$ liter air per hari pada 70\% subyek (Rigaud et al., 2017).

Beberapa studi juga menunjukkan bahwa suhu tubuh terkait dengan kebutuhan cairan selama kehamilan. Di dalam tubuh, air berfungsi dalam pengaturan suhu tubuh dengan menghasilkan, menyerap dan menghantarkan panas ke seluruh tubuh. Ketika tubuh berkeringat, penguapan berasal dari permukaan kulit dan menyebabkan suhu tubuh menurun (Santoso et al., 2011). Kehilangan cairan 6-8\% dapat meningkatkan suhu tubuh (Thompson, Manore and Vaughan, 2008).Kebutuhan cairan selama kehamilan mengalami peningkatan untuk memenuhi kebutuhan ibu dan janinnya seperti peningkatan volume darah, sirkulasi janin, serta produksi cairan amnion (Santoso et al., 2012). Ibu hamil rentan mengalami kekurangan cairan karena adanya morning sickness dan frekuensi buang air kecil yang sering (Lee and Saha, 2011; Santoso et al., 2011). Oleh karena itu, pemenuhan asupan cairan selama kehamilan menjadi hal penting untuk diperhatikan. Penelitian ini bertujuan untuk menganalisis aspek terkait dengan asupan cairan selama kehamilan, yaitu status gizi, pengetahuan dan suhu tubuh. 


\section{METODE}

\section{Desain, Waktu, dan Tempat Penelitian}

Penelitian ini merupakan observasional dengan pendekatan cross sectional, pada bulan Maret sampai September 2017 di Puskesmas Kecamatan Kebon Jeruk Jakarta Barat

\section{Populasi dan Sampel}

. Sampel ditentukan secara purposive pada ibu hamil dengan kriteria inklusi yaitu : usia kehamilan trimester dua (trimester satu morning sickness lebih sering terjadi), usia subjek 18-35 (usia produktif), melakukan pemeriksaan antenatal care di trimester satu di puskesmas tersebut. Adapun kriteria eksklusinya adalah kehamilan kembar. Jumlah subjek penelitian sebanyak 84 orang ibu hamil

\section{Pengambilan dan Analisis Data}

Data penelitian meliputi data status gizi, pengetahuan, suhu tubuh dan asupan cairan. Status gizi diperoleh dengan menganalisis indeks massa tubuh sebelum kehamilan berdasarkan catatan berat badan sebelum hamil, pengukuran tinggi serta berat badan di trimester dua. Status gizi subjek sebelum kehamilan dikategorikan menjadi: underweight (imt <18,5), normal (imt 18,5-24,8), overweight (imt 25-29,9), dan obesitas jika imt $\geq 30 \mathrm{~kg} / \mathrm{m}^{2}$ (IOM (Institute of Medicine), 2009). Pengetahuan subjek diukur dengan memberikan pertanyaan tentang asupan cairan, jawaban yang benar $<60 \%$ maka dikategorikan kurang, 60-80\% sedang dan $>80 \%$ baik (Khomsan, 2000). Suhu tubuh subjek diukur dengan termometer inframerah digital, dikategorikan normal yaitu sekitar $36-37,5^{\circ} \mathrm{C}$ dan tidak normal $<36$ atau $>37,5^{\circ} \mathrm{C}$ (Tamsuri, 2007). Asupan cairan diperoleh dengan wawancara recall 24 jam, yang merupakan rangkuman dari asupan makanan dan cairan 24 jam selama 3 hari. Asupan cairan dikategorikan kurang jika asupan cairan yang diperoleh $<90 \%$ dan cukup jika $\geq 90 \%$ (Armstrong et al., 2012).

Analisis data menggunakan aplikasi SPSS versi 17 for Windows. Tahapan awal yaitu menormalisasi data dengan uji Kolmogorov-Smirnov (jumlah sampel lebih dari 50), tetapi seluruh data pada penelitian ini tidak terdistribusi normal meskipun sudah ditransformasi sehingga menggunakan uji non parametrik yaitu spearman untuk uji bivariat. 


\section{HASIL DAN PEMBAHASAN}

Subjek dalam penelitian merupakan ibu hamil dengan usia kehamilan 16-18 minggu (trimester dua). Status gizi pada ibu hamil menunjukkan sebagian besar dalam kategori normal dengan presentase 60,8\%. Indeks massa tubuh sebelum hamil berperan dalam mewujudkan kondisi yang sehat sehingga menjadi anjuran pencapaian berat badan sebelum hamil yang sesuai, hal tersebut merupakan alasan pentingnya pengukuran antropometri selama kehamilan (Widen and Gallagher, 2014).

Pengetahuan merupakan awal dari perubahan perilaku, yang merupakan hasil tahu dan terjadi setelah proses pengamatan pada objek, sehingga pemahaman dan interpretasi dilakukan dengan tepat sampai pada tahap penerapan. (Notoatmodjo, 2010). Hasil penelitian menunjukkan subjek paling banyak memiliki pengetahuan asupan cairan yang baik dengan prersentase $44,1 \%$.

Suhu tubuh subjek sebagian besar berada pada kategori normal sebesar 86,9\%. Peningkatan pengeluaran air dan elektrolit melalui kulit dan mengakibatkan berkurangnya cairan dalam tubuh disebabkan karena meningkatnya suhu tubuh. setiap Peningkatan suhu $1^{\circ} \mathrm{C}$ diatas $38^{\circ} \mathrm{C}$ membutuhkan penambahan asupan cairan sebanyak 10-12\% (Santoso et al., 2011).

\section{Tabel 1. Distribusi Status Gizi, Pengetahuan, Suhu Tubuh dan Asupan Cairan}

\begin{tabular}{lcc}
\hline \multicolumn{1}{c}{ Variabel } & Jumlah (n) & Persentase (\%) \\
\hline Status Gizi & & \\
Overveight & 7 & 8,3 \\
Obesitas & 18 & 21,4 \\
Normal & 51 & 60,8 \\
Underveight & 8 & 9,5 \\
Pengetahuan & & \\
$\quad$ Kurang & 27 & 32,1 \\
$\quad$ Sedang & 20 & 23,8 \\
$\quad$ Baik & 37 & 44,1 \\
Suhu tubuh & & \\
$\quad$ Normal & 73 & 86,9 \\
$\quad$ Tidak Normal & 11 & 13,1 \\
Asupan Cairan & & \\
$\quad$ Kurang & 38 & 45,2 \\
$\quad$ Cukup & 46 & 54,8 \\
\hline
\end{tabular}

Kebutuhan cairan dihitung berdasarkan kebutuhan makanan dengan rumus Mosteller (1987) yaitu luas permukaan tubuh orang dewasa. Hasil penelitian menunjukkan sebanyak 54,8\% asupan cairan subjek dalam kategori cukup. 


\section{Hubungan Status Gizi dengan Asupan Cairan}

Status gizi selama kehamilan ditinjau dari indeks massa tubuh sebelum hamil dengan asupan cairan menunjukkan subjek dengan status gizi normal memiliki asupan cairan yang cukup sebanyak 38,1\%. Hasil analisis hubungan menggunakan uji spearman menunjukkan nilai $\mathrm{p}<0,05$ bermakna status gizi memiliki hubungan dengan asupan cairan. Hasil yang diperoleh serupa dengan penelitian Bardosono et al. (2016) yaitu terdapat perbedaan total asupan cairan berdasarkan kategori IMT sebelum kehamilan, ibu hamil yang kurus memiliki total asupan cairan yang lebih tinggi daripada yang gemuk. Sebuah penelitian menyatakan bahwa penumpukan lemak tubuh berhubungan dengan meningkatkan berat badan tanpa menambah jumlah air karena air dalam sel lemak yang sedikit (Buanasita, Yanto and Sulistyowati, 2015). Vij \& Joshi, (2014) mengungkapkan bahwa asupan air yang tinggi pada penderita obesitas dapat menurunkan nafsu makan, ketebalan kulit, indeks massa tubuh, berat badan, sehingga peningkatan asupan cairan banyak direkomedasikan untuk penurunan berat badan.

Tabel 2. Uji hubungan Status Gizi dengan Asupan Cairan

\begin{tabular}{lccccc}
\hline Status Gizi & \multicolumn{4}{c}{ Asupan cairan } & \multirow{2}{*}{ p Value } \\
\cline { 2 - 5 } & \multicolumn{2}{c}{ Kurang } & \multicolumn{2}{c}{ Cukup } & \\
\cline { 2 - 5 } & $\mathbf{n}$ & $\mathbf{0}$ & $\mathbf{n}$ & $\mathbf{0}$ & \\
\hline Overweight & 7 & 8,3 & 0 & 0 & 0,002 \\
Obesitas & 9 & 10,7 & 9 & 10,7 & \\
Normal & 19 & 22,6 & 32 & 38,1 & \\
Underweight & 3 & 3,6 & 5 & 6,0 & \\
\hline
\end{tabular}

Tubuh mempertahankan sekitar 73\% total cairan dari massa lemak bebas pada manusia dewasa. Hubungan konstan antara total cairan tubuh dan massa lemak bebas (total cairan tubuh $=\sim 0,73 \times$ massa lemak bebas pada orang dewasa) menjelaskan orang kurus memiliki persentase total cairan tubuh lebih tinggi daripada mereka yang kelebihan berat badan atau obesitas, pria pada umumnya memiliki total cairan tubuh lebih tinggi daripada wanita, dan persentase total cairan tubuh cenderung menurun seiring bertambahnya usia (Perrier et al., 2014).

\section{Hubungan Pengetahuan dengan Asupan Cairan}

Pengetahuan asupan cairan diperoleh dari jawaban mengenai kebutuhan air selama hamil, dampak kekurangan air bagi tubuh manfaat serta ciri-ciri air yang layak konsumsi menunjukkan dari 37 subjek yang memiliki pengetahuan yang baik, sebanyak 20,2\% memiliki asupan cairan yang cukup. 


\section{Tabel 3. Uji Hubungan Pengetahuan dengan Asupan Cairan}

\begin{tabular}{lccccc}
\hline Pengetahuan & \multicolumn{4}{c}{ Asupan cairan } & \multirow{2}{*}{ p Value } \\
\cline { 2 - 5 } & \multicolumn{2}{c}{ Kurang } & \multicolumn{2}{c}{ Cukup } & \\
\cline { 2 - 5 } & $\mathbf{n}$ & $\mathbf{0}$ & $\mathbf{n}$ & $\mathbf{0}$ & \\
\hline Kurang & 7 & 8,3 & 20 & 23,8 & 0,022 \\
Sedang & 11 & 13,1 & 9 & 10,7 & \\
Baik & 20 & 23,8 & 17 & 20,2 & \\
\hline
\end{tabular}

Berdasarkan hasil analisis, pengetahuan subjek memiliki hubungan dengan asupan cairan $(\mathrm{p}<0,05)$. Hasil yang diperoleh sejalan dengan Irwin et al. (2019) yang menunjukkan bahwa pengetahuan merupakan prediktor yang signifikan dalam asupan cairan. Tingkat pengetahuan ibu memengaruhi kesadaran untuk perilaku penerapan gizi yang baik. Pengetahuan kebutuhan air merupakan hal yang penting diketahui selama kehamilan agar ibu hamil lebih peduli akan pentingnya cairan selama hamil. Malisova et al. (2014) mengungkapkan total asupan cairan berhubungan dengan keseimbangan cairan (hidrasi). Santoso et al. (2012) mengungkapkan bahwa dibandingkan tingkat asupan cairan yang cukup, kekurangan cairan berisiko 1,32 kali dialami pada orang dengan tingkat asupan cairan $<90 \%$.

Pengetahuan adalah syarat awal dalam melakukan perubahan sikap dan perilaku gizi yang mendorong pemberian makanan yang baik (Khomsan, Anwar and Mudjajanto, 2009). Kepedulian tentang pangan yang sehat perlu diketahui saat hamil. Pentingnya kepedulian akan gizi dengan mencari informasi kesehatan sehingga dapat merubah pola konsumsi karena makanan yang dikonsumsi bermanfaaat untuk ibu serta janin, sehingga ditemukan hubungan positif antara pengetahuan gizi dengan perilaku makan ibu. Pengetahuan tentang kesehatan selama kehamilan dapat diperoleh dari berbagai media. Media cetak yang memuat informasi kesehatan seperti surat kabar dan majalah biasanya memiliki artikel kesehatan khusus yang mudah ditemukan. Media cetak yang memuat informasi kesehatan khususnya pada ibu hamil juga disediakan oleh pemerintah melalui buku kesehatan ibu dan anak yang salah satu isinya mengenai anjuran konsumsi air minum sebanyak 10 gelas per hari (Kemenkes RI, 2016). Perkembangan teknologi mempermudah penyebaran informasi, salah satunya melaui media internet sehingga informasi kesehatan dapat diakses dengan mudah.

\section{Hubungan Suhu Tubuh dengan Asupan Cairan}

Kondisi panas dan dingin tubuh sering digunakan sebagai indikatort kondisi kesehatan. Suhu tubuh subjek dalam kategori normal menunjukkan 46,4\% dalam kategori cukup asupan cairan. Berdasarkan hasil analisis menunjukkan bahwa tidak terdapat 
hubungan suhu tubuh subjek dengan asupan cairan $(\mathrm{p}>0,05)$. Penelitian sebelumnya memiliki hasil yang berbeda yaitu suhu tubuh yang menunjukkan angka lebih atau kurang dari suhu normal memungkinkan terjadinya kekurangan air sebanyak 1,54 kali pada individu dengan suhu tubuh normal (Santoso et al., 2012).

Tabel 4. Uji Hubungan Suhu Tubuh dengan Asupan Cairan

\begin{tabular}{lccccc}
\hline Suhu tubuh & \multicolumn{4}{c}{ Asupan cairan } & \multirow{2}{*}{ p Value } \\
\cline { 2 - 5 } & \multicolumn{2}{c}{ Kurang } & \multicolumn{2}{c}{ Cukup } & \\
\cline { 2 - 5 } & $\mathbf{n}$ & $\mathbf{0}$ & $\mathbf{n}$ & $\mathbf{0}$ & \\
\hline Tidak Normal & 4 & 4,8 & 7 & 8,3 & 0,089 \\
Normal & 34 & 40,5 & 39 & 46,4 & \\
\hline
\end{tabular}

Suhu tubuh yang mengalami peningkatan lebih dari $37,5^{\circ} \mathrm{C}$ dapat meningkatan penguapan melalui kulit dan pernafasan. Setiap peningkatan suhu $1^{\circ} \mathrm{C}$ lebih dari membutuhkan asupan cairan 10-12\% dari kebutuhan harian. (Santoso et al., 2011). Proses menjaga keseimbangan suhu tubuh melalui pendinginan atau pengurangan kelebihan panas di kulit diakibatkan oleh penguapan keringat yang sebaiknya disertai dengan konsumsi cairan. Kekurangan cairan terjadi akibat pengeluaran keringat dapat mengakibatkan pengurangan volume plasma, hilangnya elektrolit, serta peningkatan kekentalan plasma. Kejadian ini mengakibatkan peningkatan pengeluaran keringat dan ketidakseimbangan dalam kenaikan suhu tubuh (Popkin, D’Anci and Rosenberg, 2010). Berdasarkan teori tersebut, penurunan dan peningkatan suhu tubuh membutuhkan peningkatan asupan air. Saat penelitian secara fisik subjek dalam keadaan sehat, suhu tubuh yang tidak normal selama kehamilan merupakan hal yang wajar disebabkan ketidakstabilan hormon. Wanita mengalami peningkatan suhu basal setelah ovulasi dan terus meningkat sampai awal menstruasi akan kembali normal. Setelah ovulasi terjadi pelepasan progesteron yang menyebabkan respon hipotalamus mengatur suhu basal lebih tinggi dan meningkatkan perasaan hangat dan berkeringat (Steward and Raja, 2019).

\section{KESIMPULAN}

Terdapat hubungan antara status gizi, pengetahuan dengan asupan cairan dan tidak terdapat hubungan suhu tubuh dengan asupan cairan. Suhu tubuh tidak normal pada subjek diduga masih dalam batas toleransi tubuh sehingga tidak berhubungan dengan asupan cairan. 


\section{DAFTAR PUSTAKA}

Ariantika, A. and Mardiyati, N. L. (2017) 'Hubungan kebiasaan minum dengan status hidrasi dan kebugaran jasmani pada atlet di persatuan bulutangkis kabupaten kudus', Nutri-Sains: Jurnal Gizi, Pangan dan Aplikasinya. UIN Walisongo Semarang, 1(2), p. 10. doi: 10.21580/ns.2017.1.2.1526.

Armstrong, L. E. et al. (2012) 'Hydration Biomarkers and Dietary Fluid Consumption of Women', Journal of the Academy of Nutrition and Dietetics, 112(7), pp. 1056-1061. doi: 10.1016/j.jand.2012.03.036.

Bardosono, S. et al. (2016) 'Fluid intake of pregnant and breastfeeding women in Indonesia: A cross-sectional survey with a seven-day fluid specific record', Nutrients, 8(11), pp. 1-11. doi: 10.3390/nu8110651.

Buanasita, A., Yanto, A. and Sulistyowati, I. (2015) 'Perbedaan tingkat konsumsi energi, lemak, cairan, dan status hidrasi mahasiswa obesitas dan non obesitas', Indonesian Journal of Human Nutrition. Brawijaya University, 2(1), pp. 11-22. doi: 10.21776/ub.ijhn.2015.002.01.2.

Chang, T. et al. (2016) 'Inadequate hydration, BMI, and obesity among US adults: NHANES 2009-2012', Annals of Family Medicine. Annals of Family Medicine, Inc, 14(4), pp. 320-324. doi: 10.1370/afm.1951.

Gernand, A. D. et al. (2012) 'Maternal nutritional status in early pregnancy is associated with body water and plasma volume changes in a pregnancy cohort in rural Bangladesh', The Journal of Nutrition. Oxford University Press (OUP), 142(6), pp. 1109-1115. doi: 10.3945/jn.111.155978.

IOM (Institute of Medicine) (2009) Weight gain during pregnancy: Reexamining the guidelines. Edited by K. M. Rasmussen and A. L. Yaktine. Washington, DC: The National Academies Press.

Irwin, B. R., Speechley, M. R. and Gilliland, J. A. (2019) 'Assessing the relationship between water and nutrition knowledge and beverage consumption habits in children', Public Health Nutrition, (12). doi: 10.1017/S1368980019000715.

Kemenkes RI (2016) Buku kesehatan ibu dan anak. Jakarta: Kementerian Kesehatan RI.

Khomsan, A. (2000) Teknik pengukuran pengetahuan gizi. Institut Pertanian Bogor.

Khomsan, A., Anwar, F. and Mudjajanto, E. S. (2009) 'Pengetahuan, Sikap, Dan Praktek Gizi Ibu Peserta Posyandu', Jurnal Gizi dan Pangan, 4(1), p. 33. doi: 10.25182/jgp.2009.4.1.33-41.

Lee, N. M. and Saha, S. (2011) 'Nausea and vomiting of pregnancy', Gastroenterology Clinics of North America, 40(2), pp. 309-334. doi: 10.1016/j.gtc.2011.03.009.

Malisova, O. et al. (2014) 'Estimations of water balance after validating and administering the water balance questionnaire in pregnant women', 
International Journal of Food Sciences and Nutrition, 65(3), pp. 280-285. doi: 10.3109/09637486.2013.860585.

Mosteller, R. D. (1987) 'Simplified calculation of body-surface area', New England Journal of Medicine, 317(17), p. 1098. doi: 10.1056/NEJM198710223171717.

Notoatmodjo, S. (2010) Ilmu Perilaku Kesehatan. Jakarta (ID): Rineka Cipta.

Perrier, E. T. et al. (2014) 'From State to Process: Defining Hydration', Obesity Facts, 7(2), pp. 6-12. doi: 10.1159/000360611.

Popkin, B. M., D’Anci, K. E. and Rosenberg, I. H. (2010) 'Water, hydration, and health', Nutrition Reviews. Blackwell Publishing Inc., 68(8), pp. 439-458. doi: 10.1111/j.1753-4887.2010.00304.x.

Rigaud, M. et al. (2017) 'Assessing a tool for self-monitoring hydration using urine color in pregnant and breastfeeding women: A cross-sectional, online survey', Annals of Nutrition and Metabolism. S. Karger AG, 70(1), pp. 23-29. doi: 10.1159/000463000.

Santoso, B. I. et al. (2011) 'Air bagi kesehatan’, in. Jakarta: Centra Communications.

Santoso, B. I. et al. (2012) 'Air bagi kesehatan', in. Jakarta: Centra Communications.

Steward, K. and Raja, A. (2019) Physiology, ovulation, basal body temperature. Finlandia: StatPearls.

Tamsuri, A. (2007) Tanda-tanda vital subu tubuh. Jakarta: EGC.

Thompson, J. J., Manore, M. and Vaughan, L. (2008) 'The science of nutrition', in. San Fransisco: Benjamin Cummings.

Vij, V. A. K. and Joshi, A. S. (2014) 'Effect of excessive water intake on body weight, body mass index, body fat, and appetite of overweight female participants', Journal of Natural Science, Biology and Medicine. Medknow Publications, 5(2), pp. 340-344. doi: 10.4103/0976-9668.136180.

Widen, E. M. and Gallagher, D. (2014) 'Body Composition Changes in Pregnancy: Measurement, Predictors and Outcomes', European Journal of Clinical Nutrition, 68(6), pp. 643-652. doi: 10.1038/ejcn.2014.40. 
Halaman ini sengaja dikosongkan 